\title{
Correlation of Physical Development Indicators with Speed-Strength Performance in 11-12-Year-Old Boys
}

\author{
Almaz Faridovich Miftakhov \\ Kazan Federal University, Elabuga Institute of KFU, Russia, miftahovalmaz83@mail.ru
}

\author{
Afanasiy Afanasievich Sergin \\ North-Eastern Federal University named after M.K. Ammosov, Institute of Physical \\ Culture and Sport, Russia,aa.sergin@s-vfu.ru
}

\section{Viktor Georgievich Starostin}

North-Eastern Federal University named after M.K. Ammosov, Institute of Physical Culture and Sport, Russia,vgstaros@mail.ru

\section{Vladimir Gavrilyevich Torgovkin}

North-Eastern Federal University named after M.K. Ammosov, Institute of Physical Culture and Sport, Russia,vg.torgovkin@s-vfu.ru

\section{Olga Nikolaevna Savinkova}

Voronezh State Institute of Physical Training, Russia, nauka.vgifk@mail.ru

The paper is devoted to the issues of improving the methods of physical training. Currently, the method of teaching and training schoolchildren is developed mainly with a focus on a child's age, which does not always correspond to his or her biological maturity. These reasons together with the growing phenomenon of child acceleration reinforce the relevance of the research topic. The purpose of the study is to evaluate the impact of speed-strength exercises on the physical development and speed-strength qualities of schoolchildren aged 11-12. The authors used the measurements of anthropometric and physiometric indicators, as well as the tests that determine the level of development of speed and speed-strength qualities. The results of the research show that the physical indicators of the test group tend to increase, and during the school year, many indicators significantly change.

Keywords: physical education and training, physical development, sports result, methods of training, speed-strength performance

Citation: Miftakhov, A. F., Sergin, A. A., Starostin, V. G., Torgovkin, V. G., \& Savinkova, O. N. (2019). Correlation of Physical Development Indicators with Speed-Strength Performance in 11-12Year-Old Boys. International Journal of Instruction, 12(1), 269-282. https://doi.org/10.29333/iji.2019.12118a 


\section{INTRODUCTION}

School age is the most advantageous period for the development of all motor skills of children. The response of a child's body to physical load is different at various stages of growth and development; it ensures a greater and long-lasting effect in certain periods of a child's development. During these periods, the body's susceptibility to selectively directed impacts of the environment increases. The development of physical qualities in school-age children is uneven: the stages of their accelerated formation are followed by the periods of deceleration. Children's speed performance reaches almost limit values earlier than all other qualities. However, not all types of speed performance develop at the same pace. As the basic means of development of speed and strength performance in school-age children, one can apply exercises characterized by high strength of muscular contractions. In other words, such exercises are characterized by a ratio of strength and speed-strength characteristics of movements, in which significant strength is manifested in much less time.

Physical training is a basic component of the modern system of sports training. Improving the physical fitness of schoolchildren mostly depends on the success of developing effective tools and methods of nurturing their physical qualities: speed, strength, endurance, flexibility, and dexterity necessary in the exercise of muscular work. The relevance of the research topic is caused by the increasing requirements to the functional state of children's body (Kerić et al., 2017).

A child's physical development can be represented in the form of a complex system of dynamic qualities. The development level of the body's individual components cannot but affect the development of the entire body. Currently, the method of teaching and training schoolchildren is developed mainly with a focus on a child's age, which does not always correspond to his or her biological maturity (Croll, 2005).

Due to the difference in the rates of physical development in children of one calendar age, there are significant differences in body size proportions, the degree of development of bone and muscle systems, in sexual development, etc. (Lee, 2003). The natural development of the body of children and adolescents is characterized by heterochronicity (acceleration and retardation). In this regard, children of one calendar age are marked by significant variations in development. It follows that the calendar age of children and adolescents does not always correspond to their biological maturity (Tamozhanskaya, 2015).

The comprehensive physical development of schoolchildren can only be achieved by the systematic and skillful application of a large range of physical exercises throughout the school period. In the process of physical education, students develop and reinforce vital motor skills (Milanese et al., 2010).

\section{LITERATURE REVIEW}

According to many experts, a significant place in the process of physical education of the younger generation should be allocated to the education of speed-strength qualities, since the high level of development of these qualities greatly contributes to the 
successful labor activity of a person and achievement of high sports results (TrawickSmith, 2014).

Speed-strength exercises are widely used in physical education and sports. At the same time, the peculiarities of the effect of speed-strength exercises on children's body have been studied extremely insufficiently (Vinogradov and Okunkov, 2015). It follows that for the correct process of physical education of children, when determining the optimization of loads in exercise, it is important to take into account the individual rates of development of children and adolescents. Therefore, the above emphasizes the need for further study in the field of a differentiated approach to physical education processes, taking into account the heterochronicity of the rates and the level of physical development of children and adolescents.

To determine the status of children's physical fitness and physical development, the system of evaluating the results of schoolchildren's educational activities should be more coordinated and improved (Peleshenko, 2013). The age of adolescence (11-17 years old) is characterized by the most intensive development of all functions and internal systems of the body. During this period, a heterochronic character and high rates of physical development and formation of various functional systems of the body are observed (Vilkas and Mèlinis, 2014). There is an important regularity in the system of physical fitness and health of children, regularly engaged in physical exercises. Researchers have proved that the method of training based on competitions leads to an increase in inhibitory processes of the vegetative nervous system and a decrease in the intensity of blood circulation in children during studying (Yakimovich et al., 2014).

Modern systems of physical education, physical culture and sports are in a crisis state and cannot meet the needs of the population. The obtained results testify to the effectiveness of this modernized methodology, which was used during the school year as a new tool for shaping and revealing the sports potential of future sportsmen (Shuba et al., 2018). It was revealed that the rate of physical development of boys in the annual cycle of training varies depending on the volume and intensity of physical activity (Boraczyński and Sozański, 2015).

At the present stage of development of mankind, the interrelation between physical fitness and development of motor skills in school-age children has not been studied enough. Positive correlations have been observed between children's body fat percentage, physical fitness, and motor skills. In the process of growing up, on the contrary, there were negative correlations between body fat percentage, physical fitness, and motor skills. These results show that when growing up, boys show an opposite similarity between the fat layer and speed, flexibility and instantaneous force (Mishima et al., 2012).

The functional abilities of school-age children depend on a number of factors, including endogenous ones. It is believed that school-age boys' muscular strength withstands the negative impact of such endogenous factors as a delay in physical development, lack of body weight, short stature and asthenia (Milushkina et al., 2017). The study of the correlation of anthropometric and psychodynamic indicators in people with accelerated 
and normal physical development revealed that the level of intellect is the same, while physical indicators differ in the level of development (Meng et al., 2013).

Contemporary methods and means of sports training are very different from the methods used in the past decades, but the sporting skills and sports results of children of a certain age are growing. This is due to the acceleration of children and other reasons. Therefore, one needs to look for other, more effective methods and means of sports training. And the interaction between the physical quality and speed-strength qualities should be studied more in depth (Vandendriessche et al., 2011).

The issues related to the development of the speed-strength qualities were studied by renowned Russian scholars Motylianskaya (1956), Farfel (1960), Filin, \& Fomin (1985) and others. They found that the development of the speed-strength quantities should begin in childhood and adolescence, since already at this age the motor analyzer is formed, the foundation of future sports achievements is laid. The speed-strength training has a positive effect on the physical development.

Currently, more attention is paid to the development of speed-strength qualities in school-age children. Here, the speed-strength qualities are an ability of a person to develop maximum effort in the shortest period of time. The researchers are especially interested in studying the relationship between the speed and strength of muscle contraction due to the fact that these two physical qualities are constantly associated with the movement and determine it (Uzunović et al., 2014). Age patterns of the formation of motility elements at different stages of ontogenesis are investigated by Balsevich et al. (2009).

\section{METHOD}

Anthropometric studies were carried out using standard tools by the unified methodology of Bunak (1931). The length of the body was measured with a stadiometer. Weighing was performed on mechanical scales with a movable weight with an accuracy of $0.5 \mathrm{~kg}$. The circumference of the chest was measured with a centimeter tape, which completely adhered to the body. When measuring the circumference of the chest, the tape is laid on the back under the lower corners of the scapula along the sides of the chest on the nipples. The arms are freely lowered; the thorax is in the middle position of the respiratory excursions (Vandendriessche et al., 2011). The vital capacity of the lungs was determined using a dry spirometer. For the measurement, a person needed to slowly make the maximum breath, take a mouthpiece, pinch a nose and exhale. The measurement should be repeated three times. The force of the strongest hand was measured by a hand dynamometer; the accuracy of the measurement was $2 \mathrm{~kg}$. The strength of the back muscles was determined using a torso dynamometer.

The level of speed-strength training was determined by the following tests:

a) A standing long jump: the standing long jump was made on the floor from the initial position; the feet were parallel to the line of repulsion. The jump was made 3 times, the best result was counted. 
b) A standing triple jump. The jump is made by pushing two legs, steps by right and left legs and landing on two legs.

c) 30 and 60 meters race was conducted according to the rules of competitions in track and field athletics.

d) Throwing a stuffed ball weighing $1 \mathrm{~kg}$.

e) Chin-up.

\section{Study procedure}

The control group included schoolchildren aged 11-12. The experimental group included schoolchildren of the same age who apply some methods of track and field athletics at the lessons of Physical Education for the development of speed-strength qualities. The authors used the following set of exercises to develop the speed-strength qualities in three directions: speed-strength, strength, and speed.

Jump exercises (speed-strength training):

1) Jumping on two legs with moving forward.

2) Jumping through barriers (children's) (height 60-70 cm).

3) Jumping to the elevation $(40-60 \mathrm{~cm})$ from a position and from approach.

4) Jumping on two legs with pulling the knees to the chest.

5) Fosbury Flop.

6) Standing long jump.

Stuffed ball exercises (strength training):

1) Throwing from the bottom forward and upward with oncoming.

2) Throwing back over a head.

3) Repulsion from the chest.

Run exercises (speed training):

1) Special run exercises.

2) Exercises for the speed of response to a sudden signal or attention.

3) Linear and shuttle races.

The speed exercises were mainly used in the first half of the main part; to increase the interest of schoolchildren, a competitive method of conducting these exercises was also used.

\section{Mathematical statistics methods}

The mathematical statistics methods were used in order to process and analyze the results of the experiment. The calculation of the arithmetic mean, mean error, the 
coefficient of variation and the standard deviation was carried out on a personal computer equipped with specialized software. The further mathematical processing was carried out by comparing the averages of the Student's t-criterion $\left(\mathrm{t}_{\mathrm{cr}}\right)$ to the reliability of the difference.

If $t_{\text {estimated }}>t_{c r}$, then the difference is significant, reliable and not accidental;

if $\mathrm{t}_{\text {estimated }}<\mathrm{t}_{\mathrm{cr}}$, then the difference is not significant, random.

During the study, a strong interaction was established between the physical fitness level and speed-strength qualities in boys of secondary school age of 11-12 years. To determine the relationship between the level of physical fitness and speed-strength qualities of the schoolchildren, Spearman's rank correlation coefficient (r) was used. The mathematical value of the correlation is expressed by its coefficient from " -1 " (the maximum negative connection) to " $+1 "$ (the maximum positive connection) by decimals to the second decimal place. The quantitative measure of connection is divided into several levels:

0.99-0.9 - very strong interrelation;

0.89-0.7 - strong interrelation;

0.69-0.5 - significant interrelation;

0.49-0.3 - moderate interrelation;

0.29-0.1 - weak interrelation;

0.09-0 - no interrelation.

\section{FINDINGS}

To characterize the level of physical development of the studied contingent, anthropometric and physiometric parameters were determined including body length and weight, chest circumference at rest, chest excursions, the vital capacity of lungs, the dynamometry of the strongest hand and back strength. The results of the study showed that the physical development tends to improve; and from the beginning to the end of the school year, many qualities significantly change. The authors revealed a positive annual dynamics of physical development in both control and experimental groups.

An analysis of the dynamics of physical fitness, physical and functional preparedness in boys aged 11-12 (at $t_{\mathrm{cr}}=2.132$ ) was conducted by the authors during the 2016-2017 school year. The body length is one of the physical qualities, which increases in children gradually but unevenly. Periods of growth spurts alternate with periods of slowing growth. Systematic exercise has a positive effect on growth and other qualities (Table 1). 
Table 1

Schoolchildren's physical fitness indicators at year start and end

\begin{tabular}{|c|c|c|c|c|c|c|}
\hline & \multicolumn{3}{|c|}{ Control group } & \multicolumn{3}{|c|}{ Experimental group } \\
\hline Qualities & Year-start & Year-end & $\begin{array}{l}\text { Diffe- } \\
\text { rence }\end{array}$ & Year-start & Year-end & $\begin{array}{l}\text { Diffe- } \\
\text { rence }\end{array}$ \\
\hline 1. Body height $(\mathrm{cm})$ & $142 \pm 2.1$ & $143.8 \pm 2.2$ & 1.8 & $139.5 \pm 2.8$ & $141.3 \pm 2.9$ & 1.4 \\
\hline 2. Body weight, $(\mathrm{kg})$ & $33.6 \pm 1.8$ & $35.2 \pm 1.7$ & 1.6 & $33.85 \pm 1.7$ & $35.7 \pm 1.6$ & 1.9 \\
\hline $\begin{array}{l}\text { 3. Circumference of } \\
\text { the chest (rest) }(\mathrm{cm})\end{array}$ & $67.8 \pm 1.3$ & $69.4 \pm 1.3$ & 1.6 & $64.15 \pm 0.7$ & $65.8 \pm 0.8$ & 1.7 \\
\hline $\begin{array}{l}\text { 4. Excursion of the } \\
\text { chest }(\mathrm{cm})\end{array}$ & $4.6 \pm 0.2$ & $5.7 \pm 0.2$ & 1.1 & $4.8 \pm 0.4$ & $6.1 \pm 0.4$ & 1.3 \\
\hline $\begin{array}{l}\text { 5. Vital capacity of } \\
\text { the lungs (milliliters) }\end{array}$ & $1,660 \pm 72.4$ & $1,900 \pm 44.7$ & 240 & $1,610 \pm 551$ & $1,880 \pm 59.7$ & 270 \\
\hline 6. Back strength $(\mathrm{kg})$ & $52.1 \pm 1.7$ & $56.3 \pm 1.5$ & 4.2 & $52.4 \pm 3$ & $65.1 \pm 2.4$ & 13.0 \\
\hline $\begin{array}{l}\text { 7. Dynamometry of } \\
\text { the strongest hand } \\
(\mathrm{kg})\end{array}$ & $17.2 \pm 0.6$ & $19.3 \pm 0.7$ & 2.1 & $16.4 \pm 0.9$ & $21.9 \pm 1$ & 5.5 \\
\hline
\end{tabular}

Table 1 shows that the body length at the year-start varies significantly, only by $2.3 \mathrm{~cm}$. Thus, in the control group, the height was $142.0 \pm 2.1 \mathrm{~cm}$, and in the experimental group it was $139.9 \pm 2.8 \mathrm{~cm}$. By the end of the school year, the mean length of the body of the control and experimental groups tended to increase. In the control group, it was up to $141.3 \mathrm{~cm}$ (an increase by $1.4 \mathrm{~cm})\left(\mathrm{t}_{\text {estimated }}=0.4, \mathrm{p}>0.005\right)$, and in the experimental group $-143.8 \mathrm{~cm}(1.8 \mathrm{~cm}$ increase $)\left(\mathrm{t}_{\text {estimated }}=0.4 ; \mathrm{p}>0.05\right)$; no significant differences were found (Figure 1).

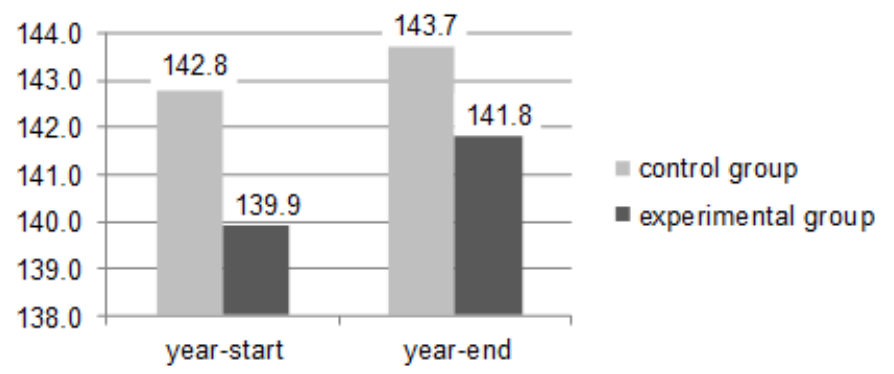

Figure 1

Schoolchildren's body height

The body weight also varies rapidly at middle school age under the influence of various factors; this is a less stable value. At secondary school age, boys have a slight increase in body weight (Figure 2). 


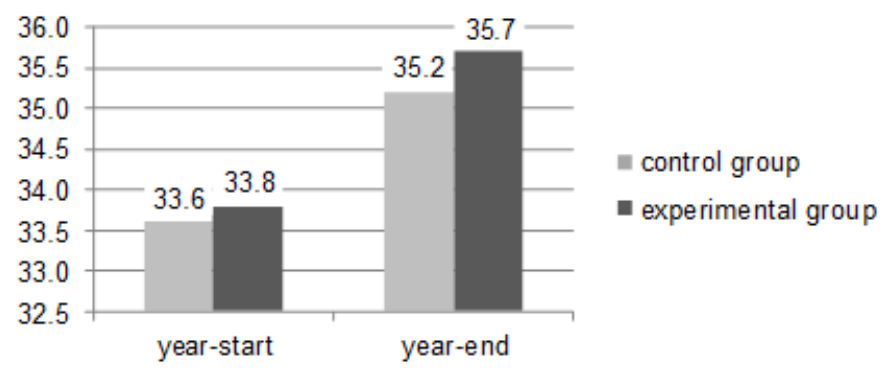

Figure 2

Schoolchildren's body weight

In the authors' example, the weight of the schoolchildren increases slightly from the beginning to the end of the school year $\left(t_{\text {estimated }}=0.7, p>0.05\right)$, in the control group by $1.6 \mathrm{~kg}$, in the experimental group by $1.9 \mathrm{~kg}\left(\mathrm{t}_{\text {estimated }}=0.6 ; \mathrm{p}>0.05\right)$. There were no significant differences.

There are significant differences $(p<0.05)$ in the circumferences of the chest of both groups under study. At the beginning of the school year, the mean value of the chest circumference in the control group was $67.8 \mathrm{~cm}$, and by the end of the school year, it increased by $1.6 \mathrm{~cm}$. In the experimental group of schoolchildren, the mean value of the chest circumference at the beginning of the school year was $64.15 \mathrm{~cm}$, by the end it was $65.8 \mathrm{~cm}$ and increased by $1.7 \mathrm{~cm}$ (Table 1). The authors also noted the increase in strength, which was determined with deadlift and dynamometry. In the deadlift, the growth in the experimental group was $13 \mathrm{~kg}$.

Despite the narrowly directed action of the exercises (development of speed-strength abilities), the authors observed a significant increase in other physical qualities, such as chest excursion and the circumference of the chest. The excursion of the chest is a value that characterizes the mobility of schoolchildren's chest (Trawick-Smith, 2014). For example, in the process of systematic training in cyclic sports, the excursion of the chest significantly increases. Also, this quantity is influenced by the features of the training process. At the beginning of the school year, the control group schoolchildren's average size of the chest excursion was $4.6 \mathrm{~cm}$, by the end of the school year it changed to $5.7 \mathrm{~cm}$ (increase $=1.1 \mathrm{~cm})\left(\mathrm{t}_{\text {estimated }}=2.2, \mathrm{p}<0.05\right)$. At the beginning of the year, the experimental group schoolchildren's average size of the chest excursion was $4.8 \mathrm{~cm}$, and by the end, it reached $6.1 \mathrm{~cm}$ (increase $=1.3 \mathrm{~cm})\left(\mathrm{t}_{\text {estimated }}=4.6, \mathrm{p}<0.05\right)$. Reliable differences in both groups were revealed.

The dynamics of changes in the vital capacity of the lungs is the same as the dynamics of changes in other qualities, so there was an increase at the end of the school year. The increase in the lung capacity is more expressed in the experimental group (Table 1). At the beginning of the school year, 1,610 milliliters in the control group increased to 1,880 $\mathrm{ml}$ by the end of the school year (increase $=270 \mathrm{ml})\left(\mathrm{t}_{\text {estimated }}=3.1, \mathrm{p}<0.05\right)$. In the experimental group at the beginning of the year, the average vital capacity of the lungs 
was $1,660 \mathrm{ml}$; by the end, it increased to $1,900 \mathrm{ml}($ increase $=240 \mathrm{ml})\left(\mathrm{t}_{\text {estimated }}=2.9\right.$, $\mathrm{p}<0.05$ ) (Figure 3).

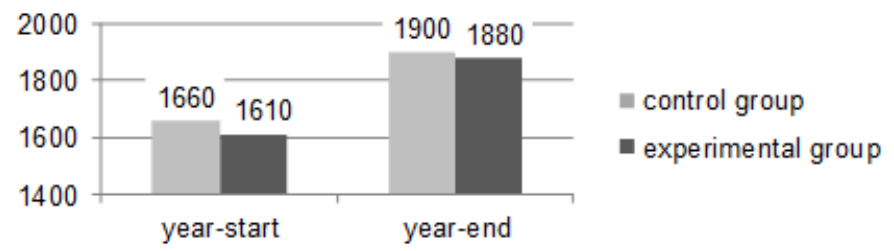

Figure 3

Vital capacity of the lungs

The strength qualities in both study groups increased. In the experimental group, the increase in strength qualities was significantly higher than in the control group. The testing of speed-strength preparedness conducted by the authors at the beginning and at the end of the school year allowed studying the manifestation of the basic motor qualities in schoolchildren of the control and experimental groups and determining the level of their development (Table 2).

Table 2

Schoolchildren's speed-strength preparedness

\begin{tabular}{|c|c|c|c|c|c|c|}
\hline & \multicolumn{3}{|c|}{ Control group } & \multicolumn{3}{|c|}{ Experimental group } \\
\hline Qualities & Year-start & Year-end & $\begin{array}{l}\text { Diffe- } \\
\text { rence }\end{array}$ & $\begin{array}{l}\text { Year- } \\
\text { start }\end{array}$ & Year-end & $\begin{array}{l}\text { Diffe- } \\
\text { rence }\end{array}$ \\
\hline 1. Long jump $(\mathrm{cm})$ & $168.5 \pm 2.6$ & $173.6 \pm 2.6$ & 5.1 & $170 \pm 2.5$ & $189.3 \pm 4$ & 19.3 \\
\hline 2. Triple jump $(\mathrm{cm})$ & $4.98 \pm 0.03$ & $5.2 \pm 0.05$ & 0.22 & $5 \pm 0.03$ & $6.4 \pm 0.05$ & 1.4 \\
\hline 3. 30 meters race $(\mathrm{sec})$ & $5.66 \pm 0.1$ & $5.24 \pm 0.05$ & 0.4 & $5.7 \pm 0.1$ & $5.1 \pm 0.1$ & 0.6 \\
\hline 4. 60 meters race $(\mathrm{sec})$ & $9.78 \pm 0.1$ & $9.56 \pm 0.1$ & 0.22 & $9.8 \pm 0.1$ & $9.29 \pm 0.04$ & 0.6 \\
\hline 5. Chin-up (times) & $3.3 \pm 0.6$ & $3.7 \pm 0.1$ & 0.4 & $2.6 \pm 0.4$ & $5 \pm 0.5$ & 2.4 \\
\hline $\begin{array}{l}\text { 6. Throwing a stuffed } \\
\text { ball (meters) }\end{array}$ & $3.01 \pm 0.1$ & $3.2 \pm 0.1$ & 0.2 & $3.16 \pm 0.1$ & $3.8 \pm 0.1$ & 0.7 \\
\hline
\end{tabular}

Table 2 presents the results of measurements of the speed-strength qualities of schoolchildren received at the beginning and at the end of the school year. The analysis of the dynamics of speed-strength qualities reflects their increase depending on the content of the training. Practice shows that many teachers still underestimate the role of speed-strength training of schoolchildren, considering it as a kind of supplement to lessons. If some teachers also use purposeful speed-strength training, then they are generally of a general developmental nature, which does not correspond adequately to the specifics of the work of the neuromuscular apparatus in running. The application method for these tools is also not ordered, and these means do not find a proper place in the overall structure of the lesson plan. At the same time, some studies have shown that 
rationally organized integrated speed-strength training provides a significant increase in the effectiveness of the entire training system. And the role of the speed-strength training is not only to increase the level of motor qualities but also in the specific training effect of the speed-strength exercises (Stolbov, 2016).

The integrated development of the speed-strength qualities significantly affects the performance in the speed-strength exercises. To determine the strength capabilities and endurance, the authors used tests such as chin-up and throwing a stuffed ball. The strength capabilities from the beginning to the end of the school year increased in both groups, but in the experimental group, they increased to a more pronounced extent (Figure 4).

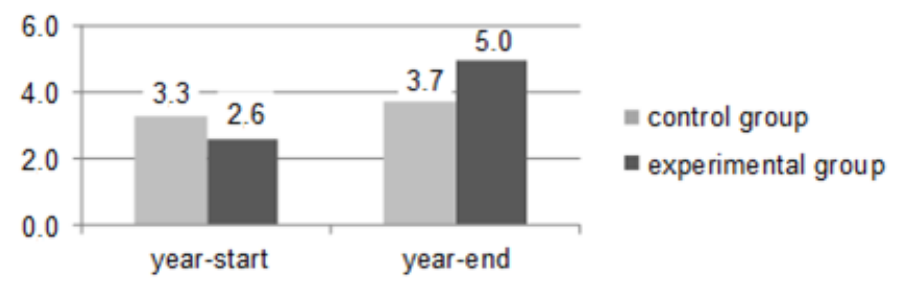

Figure 4

Chin-up (times)

In the experimental group, the increase by the end of the school year was 2.4 times; and in the control group, this quantity remained almost unchanged.

Throwing a stuffed ball also determines the strength capabilities. At the beginning of the school year in the control group, it was 3.01 meters, and by the end of the school year it increased insignificantly by 0.1 meters $\left(\mathrm{t}_{\text {estimated }}=1.3, \mathrm{p}>0.05\right.$ ), the difference is not reliable. In the experimental group at the beginning of the school year, it was $3.16 \mathrm{~m}$, and at the end of the year, it increased to $3.8 \mathrm{~m}$ (increase $=0.64 \mathrm{~m})\left(\mathrm{t}_{\text {estimated }}=5.7\right.$, $\mathrm{p}<0.05)$, the difference is significant.

The long and triple jumps show the level of the speed-strength qualities. In these test exercises, the greatest increase in results was observed in the experimental group. The long jump from a position of the control group at the beginning of the school year was $168.5 \mathrm{~cm}$, and by the end, it increased to $173.6 \mathrm{~cm}$ (increase $=5.1 \mathrm{~cm})\left(\mathrm{t}_{\text {estimated }}=0.37, \mathrm{p}\right.$ $>0.05$ ). At the beginning of the year, the experimental group schoolchildren's long jump was $170 \mathrm{~cm}$, and by the end, it reached $189.3 \mathrm{~cm}$ (increase $=19.3 \mathrm{~cm})\left(\mathrm{t}_{\text {estimated }}=1.97\right.$, $\mathrm{p}<0.05)$. There were no significant differences.

The 30 and 60 meters race shows the speed qualities. At the beginning of the year, the control group had a score of 5.66 seconds in the 30 meters race, and 5.24 seconds at the end of the school year (improvement $=0.42$ seconds) $\left(\mathrm{t}_{\text {estimated }}=3.8, \mathrm{p}<0.05\right)$. At the beginning of the year, the experimental group's $30 \mathrm{~m}$ race was $5.7 \mathrm{sec}$, and by the end, it reached $5.1 \mathrm{sec}$ (improvement $=0.6 \mathrm{sec})\left(\mathrm{t}_{\text {estimated }}=4.2, \mathrm{p}<0.05\right)$. The difference is reliable. At the beginning of the year, the control group $60 \mathrm{~m}$ race was $9.78 \mathrm{sec}$, and by the end, it reached $9.56 \mathrm{sec}$ (improvement $=0.22 \mathrm{sec})\left(\mathrm{t}_{\text {estimated }}=1.4, \mathrm{p}<0.05\right)$. The difference is not reliable. At the beginning of the year, the experimental group's $60 \mathrm{~m}$ 
race was $9.8 \mathrm{sec}$, and by the end, it reached $9.28 \mathrm{sec}$ (success $=0.52 \mathrm{sec})\left(\mathrm{t}_{\text {estimated }}=5.2\right.$, $\mathrm{p}<0.05$ ). The difference is reliable. Thus, the purposeful application of a set of exercises aimed at improving speed, speed-strength and strength capabilities in schoolchildren can significantly change the results in test exercises.

\section{DISCUSSION}

The analysis of literary sources carried out by the authors showed that the development of the speed and speed-strength qualities in schoolchildren should be carried out throughout the school year. Only if this condition is met, there will be a significant increase in speed and speed-strength qualities. The study results showed that the level of physical development and the rates of speed-strength training are within this age category.

The results of the studies carried out by the authors show that the physical development of the subjects tends to increase. The body length increased in the control group by $1.4 \%$, in the experimental group - by $1.8 \%$. The body weight from the beginning to the end of the school year in both groups increased not significantly: in the control group by $1.85 \%$, and in the experimental group by $1.6 \%$. The authors tested the speed-strength preparedness and revealed a difference in the groups. So, in the experimental group, these results were much higher than in the control group by $2.5 \%$, chin-up - by $1.3 \%$, a triple jump - by $1.2 \%, 30$ meters race - by $0.14 \%, 60$ meters race - by $0.28 \%$, throwing the stuffed ball - by $0.7 \%$. During the study, a strong interaction was established between the physical fitness and speed-strength qualities in boys of secondary school age of 11-12 years. These differences are achieved through the use of a special set of exercises to develop speed and strength.

\section{CONCLUSION}

Continuity is an important factor in the effectiveness of the process of development of speed-strength qualities. No training can be excluded from a set of exercises without compromising the achievement of the desired result (Kikot and Barchukov, 2016).

The studies carried out on a contingent of runners for short distances established that the speed-strength exercises serve as an effective means of training the speed-strength qualities of young athletes, in the performance of which the strength tends to its maximum mainly due to the increase in the rate of muscle contraction. It should be noted that the main means for the development of the speed-strength qualities and speed are jumping exercises, exercises with small weights, sprinting in various conditions (lightweight, with weights, using exercise machines). The difference in the use of these means in boys and girls is primarily in the amount and intensity of the exercises.

The criterion for assessing the speed-strength qualities and the prospects for their improvement are currently studied in the separate manifestation of the speed and strength components in their relationship with the structure of competitive exercises. As for the development of the basic components of the speed-strength qualities of young athletes carried out during exercising and in accordance with the structure of special 
exercises, these issues have not yet been adequately studied in the scientific and methodological literature and are still developed in sports practice.

The practice shows that excluding of the strength exercises from the training in the process of the speed-strength training of athletes leads to a rapid reduction in the level of the strength component, while the excessive use of them contributing to the development of the strength qualities inhibits the improvement of the speed component and, as a consequence, leads to a decrease in the level of the speed-strength qualities in general (Radulović et al., 2016).

\section{RECOMMENDED PRACTICE}

1) To improve the effectiveness of ongoing classes, it is necessary to introduce a set of exercises aimed at developing and improving a number of qualities of physical development.

2) For the optimal implementation of the objectives set at the lesson, it is necessary to strictly consider the individual characteristics of students' development.

3) To achieve the best results, it is necessary to increase the number of physical education lessons in the weekly schedule of schoolchildren's activities, in particular, to include additional classes in athletics.

4) It is necessary to optimize the educational load of students, especially when setting homework, in order to alternate their educational work and rest (differentiation of types of educational activities).

5) When scheduling, it is not recommended at the beginning of the week to put a large number of disciplines requiring a lot of intellectual effort, complex calculations, etc. The bulk of the educational intellectual load on students should be in the middle of the week. At the beginning of the week, the lessons should be less intellectually complex than in the middle of the week. Then it is necessary to smoothly increase the loads to Wednesday and on Wednesday there should be lessons of the greatest complexity. On Friday, the load should be reduced as compared to the middle of the week.

\section{REFERENCES}

Balsevich, V. K., Gorbenko, V. P., \& Novikov, V. P. (2009). The Strength and Methods of Improving It for Athletes. Moscow: Russian State University of Physical Education, Sports, Youth and Tourism.

Boraczyński, M., \& Sozański, H. (2015). Rate of Physical Development in Boys Aged 10-11 years and the Effects of Training Loads during a 12-month Soccer Program. [Dynamika rozwoju somatycznego chłopców w wieku 10-11 lat a obciazenia treningowe zrealizowane w toku 12-miesiecznego programu szkolenia w piłce noznej] Developmental Period Medicine, 19(3), 367-374.

Bunak, V. V. (1931). Methodology of Anthropometric Research. Moscow: Gosmedizdat. 
Croll, J. (2005). Body image and adolescents. In J. Stang, \& M. Story (Eds.), Guidelines for Adolescent Nutrition Services (pp. 155-166). Minneapolis, MN: University of Minnesota.

Farfel, V. S. (1960). Physiology of Sports. Essays. Moscow: Fizkultura i sport.

Filin, V. P., \& Fomin, N. A. (1985). Fundamentals of Youth Sport. Moscow: Fizkultura i sport.

Kerić, M., Rubin, P., Ujsasi, D., Fratrić, F., Radulović, N. (2017). Significance of the Differences in Motor Abilities and Morphological Characteristics between Boys and Girls aged 9 to 11 for Physical Education Optimization. Facta Universitatis, 15(1), 115123.

Kikot, V. Ya., \& Barchukov, I. S. (2016). Physical Education and Physical Training. Moscow: Unity-Dana. (p. 431).

Lee, C.P. (2003). Comparison of anthropometric characteristics and motor performance scores in malaysian boys. An inter-disciplinary approach. Budapest: Semmelweis University Budapest Doctoral School.

Meng, X. R., Wang, H. J., Fu, L. G., Dong, B., \& Ma, J. (2013). [Association between physical development and spermatorrhea during puberty among boys aged 11 to 15 years in China]. Zhonghua Yu Fang Yi Xue Za Zhi [Chinese Journal of Preventive Medicine], 47(8), 695-699.

Milanese, C., Bortolami, O., Bertucco, M., Verlato, G., \& Zancanaro, C. (2010). Anthropometry and Motor Fitness in Children Aged 6-12 years. Journal of Human Sport and Exercise, 5(2), 265-279. doi:10.4100/jhse.2010.52.14

Milushkina, O. Y., Skoblina, N. A., Prusov, P. K., Bokareva, N. A., Tatarinchik, A. A., Kozyreva, F. U., \& Moiseev, A. B. (2017). Dependence of Muscle Strength on Biological Maturation Rates and Key Variables of Physical Development in Teenage Boys, Bulletin of Russian State Medical University, 6(6), 28-33.

Mishima, T., Fujii, K., Watanabe, E., \& Seki, K. (2012). Similarities between Change of Body Fat with Age and Physical Fitness and Motor Ability Development Derived from Mutual Correlation Function-Analysis on Boys during School age-. Japanese Journal of Physical Fitness and Sports Medicine, 61(2), 201-210. doi:10.7600/jspfsm.61.201

Motylianskaya, R. E. (1956). Sports and Age. Moscow: MEDGIZ. (p. 304).

Peleshenko, I. N. (2013). Indicators of Physical Development and Physical Fitness of Schoolboys of the First Class of Secondary Schools. Pedagogics, psychology, medicalbiological problems of physical training and sports, 8, 65-68. doi:10.6084/m9.figshare.747475

Radulović, N., Mihajlović, I., Gusić, M., \& Pavlović, R. (2016). The Effects of Volume and Skinfolds on Sprinter Speed in 11-12-year old Children. Acta Kinesiologica, 10(1), 56-62. 
Shuba, L., Chukhlantseva, N., \& Shuba, V. (2018). Complex Development of Physical Characteristics of 11-12-year-old Boys Using Basketball Elements for Physical Education. Journal of Physical Education and Sport, 18(2), 739-744. doi:10.7752/jpes.2018.02108

Stolbov, V. V. (2016). History of Physical Education and Sports. Moscow: Fizkultura i sport.

Tamozhanskaya, G. V. (2015). Morphological Functional and Psychological Indicators of 11-12 years age Boys' (members of preparatory special health groups of urban and countryside schools) Development. Pedagogics, psychology, medical-biological problems of physical training and sports, 4, 43-50. doi: http://dx.doi.org/10.15561/18189172.2015.0408

Trawick-Smith, J. (2014). The Physical Play and Motor Development of Young Children: A Review of Literature and Implications for Practice. Center for Early Childhood Education Eastern Connecticut State University. Retrieved March 17, 2018, from http://www1.easternct.edu/cece/files/2014/06/BenefitsOfPlay_LitReview.pdf

Uzunović, S., Milanović, D., Pantelić, S., Kostić, R., Milanović, Z., Milić, V. (2014). The Physical Characteristics and Explosive Strength of Schoolchildren. Facta Universitatis, 12(3), 241-250.

Vandendriessche, J. B., Vandorpe, B., Coelho-E-silva, M. J., Vaeyens, R., Lenoir, M., Lefevre, J., \& Philippaerts, R. M. (2011). Multivariate Association among Morphology, Fitness, and Motor Coordination Characteristics in boys age 7 to 11. Pediatric Exercise Science, 23(4), 504-520. doi:10.1123/pes.23.4.504

Vilkas, A., \& Mèlinis, R. (2014). Changes of Physical Development of Learners (1117-year-old), Their Physical and Functional Fitness Indicators and Reference Scales. [Mokinių (11-17 metų) fizinio išsivystymo, fizinio ir funkcinio pajègumo rodiklių kaitos ypatumai amžiaus aspektu]. Pedagogika, 115(3), 105-121. doi: $10.15823 /$ p.2014.030

Vinogradov, P. A., \& Okunkov, Yu. V. (2015). Physical Education and Sports of Workers. Moscow: Sovetskii sport. (p. 172).

Yakimovich, V. S., Burlykov, V. D., \& Proshkin, S. N. (2014). The Correlation Between the Health Indicators and Physical Development of Men aged 25-30 Who Regularly Play Minifootball. Biology and Medicine, 6(3). 